Manu, J. \& Owusu-Ansah, C.M. (2019). The Impact of Demographic Factors on Pre-Service Teachers' Perception of Educational Research: Findings from a Private University

\title{
The Impact of Demographic Factors on Pre-Service Teachers' Perception of Educational Research: Findings from a Private University
}

\author{
Jacob Manu \\ University of Education, Winneba-Mampong-Ghana \\ Christopher M. Owusu-Ansah* \\ University of Education Winneba- Mampong-Ghana \\ *Corresponding Author: chrisoansah@gmail.com \\ Received : 2019-03-07 \\ Accepted : 2019-06-01
}

How to cite this paper: Manu, J. \& Owusu-Ansah, C.M. (2019). The Impact of Demographic Factors on Pre-Service Teachers' Perception of Educational Research: Findings from a Private University, Journal of Culture and Values in Education, 2(2), 38-56

\begin{abstract}
The current study sought to identify the effects of demographic factors on the perception of pre-service teachers (with diploma as their highest level of education) on the teaching and learning of the Educational Research course during the fall 2017 semester in one of the private universities in Ghana. With a survey research design, three hundred and twenty (320) preservice teachers, who were enrolled in the fall 2017 sandwich programme, were randomly sampled to participate in the study. The findings revealed significant differences between male and female pre-service teachers perception of the teaching of research, relevance of research and their statistics anxiety. Also, the age independent variable indicated a significant difference on the statistics anxiety construct only whereas the other two constructs were not significant. There were significant correlations among age, years of teaching, and statistics anxiety. The implication of the study for practice is discussed.
\end{abstract}

Keywords: Educational Research, Statistics Anxiety, Pre-service Teachers, Teaching experience

\section{Introduction}

Research methods education represents one of the finest skills that a country's educational system should seek to integrate in her curriculum in order to enable students acquire the requisite skills and motivation to conduct independent and original research. In everyday life, research findings form the basis for superior and quality personal and professional decisionmaking (Cordingley, 2015). Research, broadly speaking, helps to advance knowledge, and improve practice among several professional fields such as teacher education (Kothari \& Garg, 2015; Creswell, 2012). The study and teaching of educational statistics during pre-service education ensures the ability of the pre-service teacher to interpret educational data as a component of critical citizenship and statistical sense-making (Burrill \& Biehler, 2011). These set of skills acquired can ensure successful completion of the research project component 
Manu, J. \& Owusu-Ansah, C.M. (2019). The Impact of Demographic Factors on Pre-Service Teachers' Perception of Educational Research: Findings from a Private University

during teacher training while equipping the future teacher with the fundamental awareness of the role of research and statistics in the training of younger learners (Gresham, 2018; Hill et al., 2016).

A number of important challenges confronting educators teaching Educational Research is related to the negative research self-concept of students (Markle, 2017). However, within the instructional environment of pre-service teachers, myriads of factors influence their perception of the quality of teaching and relevance of the Educational Research course, nobly among them demographic factors (Baloğlu, Deniz, \& Kesici, 2011; Faber, Drexler, Stappert, \& Eichhorn, 2018). For example, previous research indicates that female enrolment in the Science and Mathematics related courses in universities are low (Francesconi \& Parey, 2018). Since statistics, perceived to be mathematics-related in nature (Bourne, 2018), is an integral part of the teaching of the Educational Research course, female students, for instance, are likely to develop negative attitudes and perceptions of the course.

This study is an effort to contribute to the discourse on understanding the role of demographic factors in pre-service teachers' preferences and perceptions especially in respect to subjects considered among many students to be peripheral or dispensable (Park, 2003), such as Educational Research. Despite the availability of previous studies on the topic, there is a need for more understanding of the phenomenon in the Ghanaian context as relatively little research exists in this area.

\section{Statement of the problem}

There is a growing concern of the inability of pre-service teachers to conduct their own research after they have taken the Educational Research course (Batanero \& Díaz, 2010; Estrada, Batanero, \& Lancaster, 2011). Their inability to undertake a research is demonstrated when majority of these pre-service teachers stay longer on campuses after vacation in order to complete their research projects. Even though a number of previous studies attributed a number of factors such as statistics anxiety (Huang, 2018; Markle, 2017; Lavasani et al., 2014) and negative research self-concept (Slootmaeckers et al., 2014; Zare et al., 2011) for this phenomenon, it is not clear, within the Ghanaian context, what factors are responsible for these long delays to complete research projects by pre-service teachers.

To this end, this study attempts to explore the degree to which demographic factors such as the gender of the pre-service teacher, age or number of years of teaching affect their inability to conduct their own research after they have taken the course. Age can have a serious impact on the perception of the pre-service student (Liu \& Haque 2017). Learners who have prior rich experiences in life might find it easier to relate to the teaching and learning of the course whereas those with limited experience might face some challenges. Experience is usually obtained over a period of time. On the other hand, if students are beyond the traditional university students' age; have families and face other challenges in life, learning the course would be a little challenging for such pre-service teachers. 
Manu, J. \& Owusu-Ansah, C.M. (2019). The Impact of Demographic Factors on Pre-Service Teachers' Perception of

Educational Research: Findings from a Private University

Other guiding questions to unravel this problem are: Could it be that the pre-service teachers are not able to relate to the teaching and learning strategies that their teachers adopt? Again, could it be that pre-service teachers do not attach the needed importance to the Educational Research course and for this reason put in little effort in the study of the course? Answers to these questions will help teacher educators identify the problems with the teaching of the course and devise just-in-time learning interventions for these pre-service teachers.

\section{Purpose of the study}

The purpose of the study was to use survey research design to identify the effects of demographic factors on the perception of pre-service teachers (with diploma certificates) on the teaching of Educational Research course in the fall 2017 sandwich programme at a private university in Ghana. Specifically, the study explores the effect of demographic factors such as age, gender and experience of teachers on their perception of the teaching of research; relevance of research; and statistics anxiety.

\section{Research Questions}

In connection with the above, the following research questions were posed:

1. Is there any difference in the three constructs (teaching of research, relevance of research and statistics anxiety) based on gender?

2. Is there any difference in the three constructs (teaching of research, relevance of research and statistics anxiety) based on age?

3. Is there any difference in the three constructs (teaching of research, relevance of research and statistics anxiety) based on years of teaching?

4. Is there a relationship between age and the three constructs?

5. Is there a relationship between years of teaching and the three constructs?

6. Is there a relationship between age and years of teaching of respondents?

\section{Review of Related Literature}

This review focuses on three themes that underpin the study and they are: rationale for research methods in higher education; approaches for teaching research methods in higher education; and statistics anxiety among students.

\section{Rationale for research methods in higher education}

Research skills are important outcomes of educational training. Students need to demonstrate a clear ability to conduct independent inquiry during and after their studies. It is a lifelong skill required in virtually any field of human endeavor. These vital educational outcomes are acquired through the systematic science promoted through research method courses. As a result of its universal application in the curriculum, research methods courses are usually compulsory ( $\mathrm{Ni}, 2013)$. 
Manu, J. \& Owusu-Ansah, C.M. (2019). The Impact of Demographic Factors on Pre-Service Teachers' Perception of Educational Research: Findings from a Private University

A number of studies have investigated into the goals of research methods in diverse academic contexts (Aguado, 2009; Alemanne, 2018; Canning \& Gallagher-Brett, 2010; Chu, 2015; Ciarocco, Lewandowski, \& Van Volkom, 2013; Crowe, Ceresola, \& Silva, 2014; Gray et al., 2015; Hoffman, 2013; Howard \& Brady, 2015). Most of these studies approach their aims by examining the disciplinary context and norms within which research methods is applied. As observed by $\mathrm{Ni}$ (2013), owing to its universal applicability for scientific inquiry, research methods courses have been considered core in many curricula. Pfeffer and Rogalin (2012) outlined a number of benefits (citing Schutt, Blalock and Wagenaar, 1984) for teaching research methods. Among others, they reasoned that research methods courses can expose students to the need to conduct research; it can help students understand the differences between deductive and inductive reasoning and equip them with the skills to apply appropriate methods on each of them; it can expose students to the necessity of ethics in research; and it can also help unearth potential areas for new investigation.

The goals for teaching research methods may vary as one institution and or a department may emphasize some aspects of research methods (Burrill \& Biehler, 2011). According to Aguado (2009), in the social sciences, emphases may be placed on the variety of research questions that may be asked, as well as the type of research questions that may be posed in subdisciplines within the field. Other interests may include outlining the research process to students and equipping them with data-gathering skills and use of computer software for data gathering (Hartnett, 2013; Johnston, 2006).

These goals are to remind any educator of research methods to be mindful of the pedagogical expectations of the course. In other words, teachers of research methods must outline clear instructional goals pointing to the rationale for and need to learn research methods. Such an undertaking will assure students of the need to embrace the course, contribute to student retention, and lead to re-orientation of the value of research among students (Alemanne, 2018).

\section{Approaches for teaching research methods}

The quest for the most effective pedagogical factors that enhance learning and retention of knowledge among students continues to motivate research into new instructional methods beyond the traditional lecture method. In the era of ICT, many pedagogical efforts are integrating collaborative technology and the likes (Boyle et al., 2014; Dinauer, 2018; VasquezColina, Maslin-Ostrowski, \& Baba, n.d.; Kilinc, Tarman \& Aydin, 2018).

Kappes Ramirez (2018) investigated into the preferred methodology for learning standard precautions among undergraduates in Nursing. The study found that a controlled group performed better when exposed to self-instruction via a computer simulated course. The author concludes that teaching methods that integrate ICTs are effective and preferred by students for learning. The study by Ramirez espouses valuable lessons on relevant teaching approaches for research methods, having emphasised the superior advantages of self-learning computer programmes over traditional teaching methods. This is perhaps due to the constructivist nature of technologies in nurturing independent, authentic experiences of 
Manu, J. \& Owusu-Ansah, C.M. (2019). The Impact of Demographic Factors on Pre-Service Teachers' Perception of Educational Research: Findings from a Private University

learners (Natalia \& Darren, 2016). Not surprisingly, Ni (2013) found that, despite noted challenges of persistence among students, online teaching methods for research methods is less intimidating, and improves the quality and frequency of interaction between learner and instructor. The study concludes that between classroom and online learning, effective teaching and learning is markedly improved through online learning in research methods among public administration students.

Other studies examine the role of games that facilitate teaching and learning of research methods. Games retain great pedagogic value, whether traditional or computer-based (Boyle et al., 2014; Natalia \& Darren, 2016). Natalia and Darren (2016), in their exposition of the Curveball Game, demonstrate the immense value in traditional gaming in teaching research methods. The game was a staff-student collaborative initiative at Leeds Beckett University in the United Kingdom designed to enhance problem-solving among undergraduate students in the social sciences undertaking a research project. The game involved assigning students to two groups of nine members each and assigning a problem-based task. At the end of the game, the majority of the students who participated in it viewed it as "very" or "quite" useful for, among others, understanding the research process, designing research, research ethics and methodological issues in research.

Patka, Miyakuni and Robbins (2017) explored the potential of Photovoice (PV) for teaching research methods among counsellors. According to the authors, "PV is a community-based participatory research method that involves individuals actively making meaning of the world around them". Similar to the "Curveball Game", PV was implemented as a series of processes and this involved identifying a research questions; developing a photograph and interpretation; discussing the photographs and interpretations in a group discussion; transcribing the transcript of the discussions; and analysing the resulting qualitative data. This process helped students to understand the research question development, improved their reflectivity, and the need to be ethical during the research process.

Despite the hype, game-based learning approaches in research methods do not enjoy universal appeal among different age brackets. Leyva-Moral and Camps (2015) explored the utility of the Jigsaw Technique to foster student-centred and collaborative work learning approaches in research methods among nursing students at a Spanish university. The technique is a collaborative learning approach that apportions individual responsibility for the group's success, as each individual's contribution decides the final marks for each member of the group. In their evaluation, the authors found heavy workload concerns especially among less than 22 year old students, compared to older students. Notwithstanding, $89.6 \%$ of nursing students under 22 years of age reported improvement in their team-work skills, compared to $79.6 \%$ who viewed the Jigsaw Technique in this light. Generally, the study notes that the programme was not a valuable approach to learning research methods among students compared to traditional teaching methods. This finding, though, is not to suggest that game-based methods for teaching research methods are invaluable. As pointed out in Boyle et al. (2014), the use of problem-based methods, such as games, enable students to be engaged in tasks that could 
Manu, J. \& Owusu-Ansah, C.M. (2019). The Impact of Demographic Factors on Pre-Service Teachers' Perception of Educational Research: Findings from a Private University

eventually link research to evidence-based practice helping students, in a constructivist framework, to make meaning of their lived experiences of research methods.

To this end, it may be pointed out that despite the utility of games for learning research methods, it is important to recognise that whether one chooses traditional or game-based teaching approaches, they both have their strengths and weaknesses. What is important, however, is for the instructor to recognise the necessity for effective, efficient and engaged outcomes-based learning by integrating these principles in instructional goals (Hoffman, 2013).

\section{Demographic factors and statistics anxiety}

According to Lavasani, Weisani, and Shariati (2014), statistics anxiety involves "the unstable and transient experiences of tension, fear, and intense emotion of the self-dependant neural system in a specific context and situation". It usually occurs when students are learning concepts and terms in statistics. It involves persistent lack of confidence to understand concepts, problems and theories in statistics and a resulting inability to solve questions on them. A number of studies have examined the phenomenon of statistics anxiety from different perspectives: causes and effects (Chew \& Dillon, 2014; Condron, Becker, \& Bzhetaj, 2018; Huang, 2018; Lavasani et al., 2014; Markle, 2017; Najmi, Raza, \& Qazi, 2018; Slootmaeckers et al., 2014; Zare et al., 2011); disciplinary and sex differences (Baloğlu, Deniz, \& Kesici, 2011; Bourne, 2018; Faber, Drexler, Stappert, \& Eichhorn, 2018; Gray et al., 2015; Najmi et al., 2018; Onwuegbuzie \& Daley, 1999; Paechter, Macher, Martskvishvili, Wimmer, \& Papousek, 2017; Rodarte-Luna \& Sherry, 2008; Tonsing, 2018; Ulrich, n.d.; Walsh \& Ugumba-Agwunobi, 2002); and strategies for overcoming statistics anxiety (Boyle et al., 2014; Ciarocco et al., 2013; Dinauer, 2018; Dowker, Sarkar, \& Looi, 2016; Hartnett, 2013), among others. Statistics anxiety has been attributed to a number of causes. According to Slootmaeckers et al. (2014), despite numerous causes of the phenomenon of statistics anxiety, students experience this as a result of misconceptions on the difficulty of statistics and mathematics, and also due to the negative influence of peers. In their study, Slootmaeckers et al. (2014) identified three factors with the potential for instigating statistics anxiety among students: dispositional, course-related, and person-related factors. Dispositional factors are the psychological and emotional characteristics and this involves negative attitudes, perceptions, and perceived weak mathematical skills of students. Whereas course-related factors, also described as situational factors, involve prior experiences with statistics such as bad grades, how the course is taught, as well as negative experiences of students with instructors; person-related factors are concerned with environmental factors such as demographics of students: age, gender, and prior educational attainment among others. The authors noted that even though all three factors have significant effect on statistics anxiety, it is important to focus on the course-related factors, as the other two cannot be controlled by the institution administering the course. The findings revealed that all three factors affect students' perception of statistics and that there was a need to integrate statistics into the general curriculum to not only dispel this fear, but also to foster interest in, and ensure retention of statistical skills. 
Manu, J. \& Owusu-Ansah, C.M. (2019). The Impact of Demographic Factors on Pre-Service Teachers' Perception of

Educational Research: Findings from a Private University

Gender has been found as a factor for statistics anxiety among students. Chew and Dillon (2014) explored the relationship between statistics anxiety and the personality traits using multivariate research methods. The study found that different personalities experienced statistics anxiety differently. As a result, there was a need for adapted instructional approaches to different personalities. In particular, they found, among others, that females scored higher on the factor of "Agreeableness" than their male counterparts, that is, they were more likely to seek help when they experienced statistics anxiety than males.

Similarly, Zare et al. (2011) posits that cognitive and motivational factors are positively correlated to statistics anxiety. They averred that students' intentions for studying statistics are predicted by their achievement goals which may be one of mastery, approach-performance and avoidance performance. The study found that mastery factors have a negative correlation with statistics anxiety, whereas avoidance performance goals exert a positive effect on statistics anxiety of students.

The significance of these studies is that students who approach statistics with a positive attitude excel, while students who have the tendency to avoid statistics have a higher tendency to experience failure in the subject.

\section{Method}

The purpose of the current study was to identify the perception of under-graduate pre-service teachers on the teaching and learning of Educational Research as a course in one of the private universities in Ghana. The students in this class were pre-service teachers who had minimum teaching requirement (diploma). A total of 320 under-graduate pre-service teachers (representing 40\%), were selected through simple random sampling. However, after the screening of the data, seven respondents were deleted on the basis of not responding important items. The number was therefore reduced to 313 (representing 39.1\%). The sample size is in line with Krejcie and Morgan (1970).

The study was conducted at the time when these pre-service teachers were doing Educational Research at level 300 of their sandwich programme. For this reason, they could honestly assess the teaching of the course and report to the researchers appropriately. To obtain the sample, the instrument was administered to all the level 300 students (800). After the pre-service teachers returned the questionnaire, the return questionnaires were given serial numbers from one up to 800 . Afterwards, the researchers wrote numbers from one to 800 on a paper strips and placed them in a bowl. After series of shaking the bowl, 320 of these papers strips were hand-picked (40\%). The researchers used the numbers picked randomly from the draw to select their corresponding questionnaires. After screening the data, the sample size was reduced to 313 respondents for analysis.

The questionnaire consisted of quantitative items only. The questionnaire was broken into three sub-sections as Perceived teaching of research; perceived relevance of research; and perceived statistics anxiety. Each of the sub-sections had eight items. The researchers designed 
Manu, J. \& Owusu-Ansah, C.M. (2019). The Impact of Demographic Factors on Pre-Service Teachers' Perception of Educational Research: Findings from a Private University

their own instrument. The statistics anxiety construct was made up of positive statements but was later reversed coded so that higher score in the construct would indicate the presence of statistics anxiety among respondents. To assure consistency of the quantitative measures, factor analysis of the three constructs were conducted. The Cronbach Alpha of the items for the construct perceived teaching of research yielded 0.78 ; the perceived relevance of research had 0.62; while the perceived statistics anxiety indicated 0.86 . Based on the reliability tests, the researchers could compute the items together to get the required constructs as outlined above.

Table 1: Test of reliability of the three constructs

\section{Constructs Measuring Items (5=Strongly Agree, 4=Agree, 3=Neutral, Mean Cronbach 2=Disagree, $1=$ Strongly Disagree) \\ Alpha}

1. The class assignments were done individually.

2. The final examination in research was paper and pencil test. $\quad 3.01$

3. The teacher knew how to teach research. 4.00

4. Other students understood what was taught in class. $\quad 3.49$

5. I was confident of conducting my own research after class. $\quad 3.22$

6. I understood the basics of research after the class. 3.57

7. I have conducted a research on my own. 2.99

8. I will recommend the teacher for other students for research. $\quad 3.76$

1. I have been explained in detail the importance of research.

2. Research is only useful to scientists (inverted).

3. Research should be introduced at the basic school level.

4. Research is a natural thing that we do on daily basis.

5. Research courses are always taught well.

6. Research is important to decision-taking.

7. My students have undertaken a research project before.

8. We can solve local and national issues with research

1. I have taken a statistics class before.

2. I always enjoy learning statistics.

3. I do not have any fears for learning statistics.

3.60

4. Statistics should be mandatory for all university students.

3.60

0.86

5. The teaching of statistics is not a problem at all.

3.47

6. I am looking forward to taking another statistical class. 3.52

7. Statistics is important to all students.

4.13

After running the frequencies for the three constructs (teaching of research, relevance of research, and statistics anxiety), the mean and standard deviations were: teaching of research (3.41[0.82]), relevance of research (3.58[0.66]), and statistics anxiety (3.70[0.97]), respectively. The overall averages and standard deviations for the three constructs were close with a range 
Manu, J. \& Owusu-Ansah, C.M. (2019). The Impact of Demographic Factors on Pre-Service Teachers' Perception of

Educational Research: Findings from a Private University

of 0.29 for the mean and 0.31 for the standard deviation. The findings imply that the perception of pre-service teachers on these constructs were similar. However, the standard deviation of the statistics anxiety was the highest indicating that respondents did not have similar rating as compared to the other two constructs.

The researchers, as part of exploring the demographic background of respondents, investigated their gender distribution. The analysis indicated that 237 were males (75.7\%) while 76 were females (24.3\%). The data seem to indicate that the number of males in this private university was approximately three times the size of the female counterpart.

Table 2: Gender Distribution of Respondents

\begin{tabular}{lll}
\hline Gender & Frequency & Percentages \\
\hline Male & 237 & 75.7 \\
Female & 76 & 24.3 \\
\hline Total & 313 & 100 \\
\hline
\end{tabular}

(Field data, 2018)

Age was another important factor the researchers explored. From the data, under-graduate university students' age was categorized into three. These were 20-26, 27-29, and 30 and above. As indicated below, the 20-26 group had 97 respondents (31\%), 27-29 had 126 (40.3\%) whereas the last group recorded 90 respondents (28.7\%). With a mean age of 28.2 and standard deviation of 4.1, it was clear that majority of the respondents did not fall within the traditional age bracket (21-24 years). Again, it was more likely to have some outliers in the age distribution.

Table 3: Age Distribution of the Respondents

\begin{tabular}{lll}
\hline Age & Frequency & Percentages \\
\hline $20-26$ & 97 & 31.0 \\
$27-29$ & 126 & 40.3 \\
30 and Above & 90 & 28.7 \\
\hline Total & 313 & 100 \\
\hline
\end{tabular}

(Field data, 2018) 
Manu, J. \& Owusu-Ansah, C.M. (2019). The Impact of Demographic Factors on Pre-Service Teachers' Perception of Educational Research: Findings from a Private University

\section{Results and Discussion}

RQ1: Is there any difference in the three constructs (teaching of research, relevance of research and statistics anxiety) based on gender?

The researchers determined whether there was any difference in the responses of the preservice teachers in the three constructs based on their gender. In other words, did gender have any impact on how they rated the various constructs? To answer this question, independent samples t-test statistical procedure was run for the three constructs. After the procedure, the means and standard deviations were as follows: Mean $=28.17, S D=6.430$ against Mean $=24.63$, $S D=6.314$ (teaching of research); Mean $=29.32, S D=5.220$, against Mean $=26.75, S D=5.047$ (relevance of research); and Mean $=17.56, S D=7.327$ versus Mean=20.92, $S D=8.764$ (statistics anxiety) for males and females pre-service teachers respectively. Interestingly, there were significant differences between males and females in terms of how they perceived the teaching of research, the relevance of research and statistics anxiety.

This finding seems to indicate that male pre-service teachers are more likely to have advanced knowledge in research. Again, they were more likely to view research as a relevant subject of study. Finally, male pre-service teachers are more likely to have lower statistics anxiety than their female counterparts. This result is confirmed in Förster and Maur (2015) who found significant anxiety in two out of three dimensions in statistics anxiety among females. This finding is also supported in Chew and Dillon (2014), who found that the more interested a student was in a subject, the less anxious they were about it; which may likely lead to a better performance in the subject. From the finding, there appears to be a need for statistics lecturers who motivate and inspire learners to develop a deeper interest in educational research methods as a way of overcoming their fears and pessimism of the course.

Table 4: Test of group differences based on gender

\begin{tabular}{lllll}
\hline Constructs & $d f$ & $t$ & Effect size & $p$-value \\
\hline Teaching of research & 295 & 4.107 & 0.5 & .000 \\
$\begin{array}{l}\text { Relevance } \\
\text { research }\end{array}$ & 298 & 3.700 & 0.5 & .000 \\
Statistics anxiety & 297 & -3.257 & 0.4 & .001 \\
\hline
\end{tabular}

(Field data, 2018)

RQ2: Is there any difference in the three constructs (teaching of research, relevance of research and knowledge statistics) based on age?

Across ages of the university students, the researchers wanted to find whether there was any difference as they responded to the three constructs. Since age had three categories (21-26, $27-29, \& 30$ and above), the one-way ANOVA was used to run the statistical procedure. Again, the Bonferroni test was used as a post-hoc in order to locate where the differences existed within the ages. At the end of the test, the analysis indicated that there was no difference in 
Manu, J. \& Owusu-Ansah, C.M. (2019). The Impact of Demographic Factors on Pre-Service Teachers' Perception of

Educational Research: Findings from a Private University

terms of age on teaching of research and relevance of research. However, there was a significant difference in the statistics anxiety construct. The post hoc test indicated that significant differences existed between ages $21-26$ and 30 years and above. The results seem to suggest that university students within the ages of 21-26 had lower statistics anxiety level compared to their course mates who were 30 years or above. This result also conforms to that of Baloğlu et al. (2011) who found a positive relationship between older students above 27 and higher statistics anxiety.

Table 5: Test of group differences based on age

\begin{tabular}{|c|c|c|c|c|c|}
\hline Constructs & & $d f$ & $f$ & Effect size & $p$-value \\
\hline $\begin{array}{l}\text { Teaching } \\
\text { research }\end{array}$ & of & $(2,294)$ & 1.128 & $\mathrm{n} / \mathrm{a}$ & .325 \\
\hline $\begin{array}{l}\text { Relevance } \\
\text { research }\end{array}$ & of & $(2,297)$ & .713 & $\mathrm{n} / \mathrm{a}$ & .491 \\
\hline Statistics anxiety & & $(2,296)$ & 6.128 & 0.3 & .002 \\
\hline
\end{tabular}

(Field data, 2018)

RQ3: Is there any difference in the three constructs (teaching of research, relevance of research and knowledge statistics) based on years of teaching/experience?

The research participants were all pre-service teachers with diploma as their highest level of education. As a result, the researchers wanted to know whether the number of years preservice teachers have taught had any impact on their perception across the three constructs. The number of years' variable was grouped into zero to two years, three years, and four years and above. The one-way ANOVA statistical procedure indicated that there was no significant difference in the perception of the pre-service teachers on the three main constructs, based on their years of teaching. The finding seems to imply that the number of years the participants taught did not change their views and opinions on research as a course of study. This result finds support in a recent study by Gresham (2018) which suggests that all pre-service teachers, irrespective of their teaching experience, exhibit mathematics anxiety.

Table 6: Test of group differences based on years of teaching

\begin{tabular}{|c|c|c|c|c|}
\hline Constructs & $d f$ & $f$ & $\begin{array}{l}\text { Effect } \\
\text { size }\end{array}$ & $p$-value \\
\hline $\begin{array}{l}\text { Teaching } \\
\text { research }\end{array}$ & $(2,294)$ & .186 & $\mathrm{n} / \mathrm{a}$ & .831 \\
\hline $\begin{array}{l}\text { Relevance of } \\
\text { research }\end{array}$ & $(2,297)$ & .205 & $\mathrm{n} / \mathrm{a}$ & .815 \\
\hline Statistics anxiety & $(2,296)$ & .918 & $\mathrm{n} / \mathrm{a}$ & .401 \\
\hline
\end{tabular}

(Field data, 2018) 
Manu, J. \& Owusu-Ansah, C.M. (2019). The Impact of Demographic Factors on Pre-Service Teachers' Perception of

Educational Research: Findings from a Private University

RQ4: Is there a relationship between age and the three constructs?

The assumption of the researchers was that there should have been a relationship between "the more people grow older", "the more their understanding". For this reason, the researchers run the Pearson product-moment correlation of age of the pre-service teachers against all the three constructs. Contrary to the assumption of the researchers, only the teaching of research dimension indicated a positive coefficient (.034). However, there was no significant relationship between age and the teaching of research. The other two constructs (relevance of research and statistics anxiety) had a negative relationship with age (-.013 and -.159). As displayed in Table 7 , there was a significant negative correlation between age and pre-service teachers' statistics anxiety. This finding seemed to imply that the older the respondents, the less knowledge they had in statistics $(r=-0.159, p=0.006)$. This finding could be explained in several ways. One may relate this finding to that of $R Q 2$ which found that the older a teacher, the more anxious they could be in statistics (Baloğlu et al., 2011). Furthermore, from RQ1, it was revealed that the more anxious a student was in statistics, the lower their performance in statistics. Therefore, it can be concluded that older pre-service teachers may exhibit less knowledge in statistics as a result of their persistent anxiety of statistics, and not necessarily because they are 30 years or above.

Table 7: Relationship between age and the three constructs

Constructs $(r) \quad p$-value

Age/teaching of research

Age/relevance of research

Age/statistics anxiety
.034

$-.013$

$-.159 * *$
.560

.817

.006

(Field data, 2018) Correlation is significant at the 0.01 level (2-tailed)

RQ5: Is there a relationship between years of teaching and the three constructs?

Experience is an important factor that educators use to indicate who qualifies to be given portfolios within their profession. The researchers wanted to find out whether there was a relationship between the experience of pre-service teachers as demonstrated through the numbers of years pre-service teachers have been teaching as against the teaching of research, relevance of research and statistics anxiety. Once again, the Pearson product-moment correlation statistical procedure was used. The analysis indicated that all three constructs had a negative relationship with years of teaching. The relationships were so weak to the extent that two of them (teaching of research and relevance of research had less than 0.1 coefficient (-.017 and -.021). Among the three constructs, only the statistics anxiety dimension had a significant negative correlation with years of teaching $(r=-.188, p=.001)$. The implication of the finding is that the longer pre-service teachers stayed in the teaching profession, the less knowledge they had in statistics. As found in our subsequent analysis, there is a positive 
Manu, J. \& Owusu-Ansah, C.M. (2019). The Impact of Demographic Factors on Pre-Service Teachers' Perception of Educational Research: Findings from a Private University

relationship between older pre-service teachers and the longer teaching experience. Since the most experienced pre-service teachers are likely to suffer from statistics anxiety, Gresham (2018) advocates in-service continuous professional development programmes as a measure to mitigate mathematics anxiety among older, experienced pre-service teachers.

Table 8: Relationship between years of teaching and the three constructs

\begin{tabular}{lll}
\hline Constructs & $(r)$ & $p$-value \\
\hline Years of teaching/teaching of research & -.017 & .775 \\
Years of teaching/relevance of research & -.021 & .721 \\
Years of teaching/statistics anxiety & $.188^{* * *}$ & .001 \\
\hline
\end{tabular}

(Field data, 2018) Correlation is significant at the 0.001 level (2-tailed)

RQ6: Is there a relationship between age and years of teaching of respondents?

It might be obvious to find that, generally speaking, older people in the teaching profession are more likely to have taught for a longer time than the younger ones in the profession. Though this was obvious, the researchers wanted to know whether there was statistical evidence to support the stance. After running the Pearson product-moment correlation between age and years of teaching, the findings indicated that there was a strong significant positive correlation between the two variables $(r=.523, p=.000)$. The findings implied that the older the respondents, the more experienced they were in the teaching profession.

Table 9: Relationship between age and years of teaching

Construct $(r) \quad p$-value

$\begin{array}{lll}\text { Age/years of teaching } & .523^{* * *} & .000\end{array}$

Correlation is significant at the 0.001 level (2-tailed)

\section{Conclusion}

In conclusion, the current study has revealed two major findings that teacher educators teaching Educational Research have to be mindful of when designing and teaching the course. First, female pre-service teachers are more likely to have a somewhat less knowledge in the teaching of research, a negative perception of the relevance of research and unsurprisingly, a higher statistics anxiety. Second, age is a factor to consider when teaching the Educational Research course. In spite of the challenges stated above, a significant number of the respondents believed that the Educational Research course is relevant to pre-service teachers in their personal and professional lives. Again, the overall mean score of 3.4 on the perception of pre-service teachers on the teaching of Educational Research course is an indication that the 
Manu, J. \& Owusu-Ansah, C.M. (2019). The Impact of Demographic Factors on Pre-Service Teachers' Perception of

Educational Research: Findings from a Private University

course is not being facilitated in a way that will help pre-service teachers develop the required competencies to embark on research on their own. To obtain a deeper understanding of this phenomenon, it may be needful to use qualitative research design to identify the underlying reasons why pre-service teachers fail to conduct their own research after enrolling in the course. Also, there is a need to look into the reasons why age and gender have such significant impact on the perception of Educational Research courses among pre-service teachers.

\section{Implications for Practice}

The purpose of the study was to use survey research design to identify the perception of preservice with diploma certificates on the teaching of Educational Research course in the Fall 2017 Sandwich programme. Based on the findings, the implications for practice are discussed as follows:

1. There is the need for Educational Research teachers to design short surveys to collect data on gender and age distribution of the students who enroll in the course. Such a practice will allow the teacher to know how to create instructional interventions that will be developmentally appropriate for them.

2. Again, the hiring of teachers, and the teaching of Educational Research courses should be reviewed at the various institutions of higher learning to make sure competent teachers with the requisite terminal degrees in Educational Research teach the course. Such practice is more likely to reduce the anxiety levels of students who are not inclined to statistics.

3. The teaching of Educational Research should be incorporated into the mainstream of our educational system at all levels. Since research is a life skill that students will need in their personal and professional lives, it is important that the course is introduced at an early age in order to improve upon students' analytical and reasoning skills. 
Manu, J. \& Owusu-Ansah, C.M. (2019). The Impact of Demographic Factors on Pre-Service Teachers' Perception of

Educational Research: Findings from a Private University

\section{References}

Aguado, N. A. (2009). Teaching Research Methods: Learning by Doing. Journal of Public Affairs Education, 15(2), 251-260. https://doi.org/10.1080/15236803.2009.12001557

Alemanne, N. D. (2018). Teaching Research Methods in LIS. 16.

Baloğlu, M., Deniz, M. E., \& Kesici, Ş. (2011). A descriptive study of individual and cross-cultural differences in statistics anxiety. Learning and Individual Differences, 21(4), 387-391. https://doi.org/10.1016/j.lindif.2011.03.003

Batanero, C., \& Díaz, C. (2010). Training teachers to teach statistics: What can we learn from research? Statistique et enseignement, 1(1), 5-20, Retrieved from. http:// statistiqueetenseignement.fr/ojs/.

Bourne, V. J. (2018). Exploring Statistics Anxiety: Contrasting Mathematical, Academic Performance and Trait Psychological Predictors. Psychology Teaching Review, 24(1), 35-43.

Boyle, E. A., MacArthur, E. W., Connolly, T. M., Hainey, T., Manea, M., Kärki, A., \& van Rosmalen, P. (2014). A narrative literature review of games, animations and simulations to teach research methods and statistics. Computers \& Education, 74, 1-14. https://doi.org/10.1016/j.compedu.2014.01.004

Burrill, G., \& Biehler, R. (2011). Fundamental Statistical Ideas in the School Curriculum and in Training Teachers. In C. Batanero, G. Burrill, \& C. Reading (Eds.), Teaching Statistics in School Mathematics-Challenges for Teaching and Teacher Education (Vol. 14, pp. 57-69). https://doi.org/10.1007/978-94-007-1131-0_10

Canning, J., \& Gallagher-Brett, A. (2010). Building a bridge to pedagogic research: teaching social science research methods to humanities practitioners. Journal of Applied Research in Higher Education, 2(2), 4-9. https://doi.org/10.1108/17581184201000009

Chew, K. H. P., \& Dillon, D. B. (2014). Statistics Anxiety and the Big Five Personality Factors. Procedia - Social and Behavioral Sciences, 112, 1177-1186. https://doi.org/10.1016/j.sbspro.2014.01.1282

Chu, H. (2015). Research methods in library and information science: A content analysis. Library \& Information Science Research, 37(1), 36-41. https://doi.org/10.1016/j.lisr.2014.09.003

Ciarocco, N. J., Lewandowski, G. W., \& Van Volkom, M. (2013). The Impact of a Multifaceted Approach to Teaching Research Methods on Students' Attitudes. Teaching of Psychology, 40(1), 20-25. https://doi.org/10.1177/0098628312465859 
Manu, J. \& Owusu-Ansah, C.M. (2019). The Impact of Demographic Factors on Pre-Service Teachers' Perception of Educational Research: Findings from a Private University

Condron, D. J., Becker, J. H., \& Bzhetaj, L. (2018). Sources of Students' Anxiety in a Multidisciplinary Social Statistics Course. Teaching Sociology, 0092055X18780501.

Cordingley, P. (2015). The contribution of research to teachers' professional learning and development. Oxford Review of Education, 41(2), 234-252.

Creswell, J. W. (2012). Educational research: planning, conducting, and evaluating quantitative and qualitative research. Boston: Pearson Education, Inc.

Crowe, J., Ceresola, R., \& Silva, T. (2014). Enhancing student learning of research methods through the use of undergraduate teaching assistants. Assessment \& Evaluation in Higher Education, 39(6), 759-775.

Dinauer, L. (2018). 9. Beating anxiety and building community: best practices for teaching doctoral research methods and statistics online. Advancing Doctoral Leadership Education Through Technology, 137.

Dowker, A., Sarkar, A., \& Looi, C. Y. (2016). Mathematics anxiety: what have we learned in 60 years? Frontiers in Psychology, 7, 508.

Estrada, A., Batanero, C., \& Lancaster, S. (2011). Teachers' Attitudes Towards Statistics. In C. Batanero, G. Burrill, \& C. Reading (Eds.), Teaching Statistics in School Mathematics-Challenges for Teaching and Teacher Education (Vol. 14, pp. 163-174). https://doi.org/10.1007/978-94007-1131-0_18

Faber, G., Drexler, H., Stappert, M. A., \& Eichhorn, B. J. (2018). Measuring Education Science Students 'Statistics Anxiety.

Förster, M., \& Maur, A. (2015). Statistics anxiety and selfconcept of beginning students in the social sciences-a matter of gender and socio-cultural background. Zeitschrift Für Hochschulentwicklung (ZfHE), 10(4), 67-90.

Francesconi, M., \& Parey, M. (2018). Early gender gaps among university graduates. European Economic Review, 109, 63-82. https://doi.org/10.1016/j.euroecorev.2018.02.004

Gray, C., Turner, R., Sutton, C., Petersen, C., Stevens, S., Swain, J., ... Thackeray, D. (2015). Research methods teaching in vocational environments: developing critical engagement with knowledge? Journal of Vocational Education \& Training, 67(3), 274-293. https://doi.org/10.1080/13636820.2015.1050443

Gresham, G. (2018). Preservice to Inservice: Does Mathematics Anxiety Change With Teaching Experience? Journal of Teacher Education, 69(1), 90-107. https://doi.org/10.1177/0022487117702580 
Manu, J. \& Owusu-Ansah, C.M. (2019). The Impact of Demographic Factors on Pre-Service Teachers' Perception of

Educational Research: Findings from a Private University

Hartnett, J. L. (2013). Stats on the Cheap: Using Free and Inexpensive Internet Resources to Enhance the Teaching of Statistics and Research Methods. Teaching of Psychology, 40(1), 5255. https://doi.org/10.1177/0098628312465865

Hill, F., Mammarella, I. C., Devine, A., Caviola, S., Passolunghi, M. C., \& Sz\Hucs, D. (2016). Maths anxiety in primary and secondary school students: Gender differences, developmental changes and anxiety specificity. Learning and Individual Differences, 48, 45-53.

Hoffman, E. S. (2013). Beyond The Flipped Classroom: Redesigning A Research Methods Course For e3 Instruction. Contemporary Issues in Education Research (CIER), 7(1), 51. https://doi.org/10.19030/cier.v7i1.8312

Howard, C., \& Brady, M. (2015). Teaching social research methods after the critical turn: challenges and benefits of a constructivist pedagogy. International Journal of Social Research Methodology, 18(5), 511-525. https://doi.org/10.1080/13645579.2015.1062625

Huang, L. (2018). A Mixed Method Investigation of Social Science Graduate Students' Statistics Anxiety Conditions Before and After the Introductory Statistics Course. International Journal of Higher Education, 7(3), 156.

Johnston, L. (2006). Software and Method: Reflections on Teaching and Using QSR NVivo in Doctoral Research. International Journal of Social Research Methodology, 9(5), 379-391. https://doi.org/10.1080/13645570600659433

Kappes Ramirez, M. S. (2018). Influence of undergraduate nursing student teaching methods on learning standard precautions and transmission-based precautions: Experimental research. Nurse Education Today, 61, 101-105. https://doi.org/10.1016/j.nedt.2017.11.007

Kilinc, E., Tarman, B. \& Aydin, H. (2018). Examining Turkish social studies teachers' beliefs about barriers to technology integration, TechTrends, 62(3),221-223.

https://doi.org/10.1007/s11528-018-0280-y

Krejcie, R. V., \& Morgan, D. W. (1970). Determining sample size for research activities. Educational and psychological measurement, 30(3), 607-610.

Kothari, C.R., \& Garg, G. (2015). Research methodology: Methods and techniques (3 ${ }^{\text {rd }}$ ed.). Daryaganj, New Delhi: New Age International Publishers.

Lavasani, M. G., Weisani, M., \& Shariati, F. (2014). The Role of Achievement Goals, Academic Motivation in Statistics Anxiety: Testing a Causal Model. Procedia - Social and Behavioral Sciences, 114, 933-938. https://doi.org/10.1016/j.sbspro.2013.12.810 
Manu, J. \& Owusu-Ansah, C.M. (2019). The Impact of Demographic Factors on Pre-Service Teachers' Perception of Educational Research: Findings from a Private University

Leyva-Moral, J. M., \& Riu Camps, M. (2016). Teaching research methods in nursing using Aronson's Jigsaw Technique. A cross-sectional survey of student satisfaction. Nurse Education Today, 40, 78-83. https://doi.org/10.1016/j.nedt.2016.02.017

Liu, L., \& Haque, M. D. (2017). Age Difference in Research Course Satisfaction in a Blended Ed. D. Program: A Moderated Mediation Model of the Effects of Internet Self-Efficacy and Statistics Anxiety. Online Journal of Distance Learning Administration, 20(2), n2.

Markle, G. (2017). Factors Influencing Achievement in Undergraduate Social Science Research Methods Courses: A Mixed Methods Analysis. Teaching Sociology, 45(2), 105-115. https://doi.org/10.1177/0092055X16676302

Najmi, A., Raza, S. A., \& Qazi, W. (2018). Does statistics anxiety affect students' performance in higher education? The role of students' commitment, self-concept and adaptability. International Journal of Management in Education, 12(2), 95-113.

Natalia, G., \& Darren, N. (2016). Making Curveball: Working with Students to Produce a Game that can 'liven up' Research Methods and Ethics Teaching in the Social Sciences. Procedia Social and Behavioral Sciences, 228, 396-401. https://doi.org/10.1016/j.sbspro.2016.07.060

Ni, A. Y. (2013). Comparing the Effectiveness of Classroom and Online Learning: Teaching Research Methods. Journal of Public Affairs Education, 19(2), 199-215. https://doi.org/10.1080/15236803.2013.12001730

Onwuegbuzie, A. J., \& Daley, C. E. (1999). Perfectionism and statistics anxiety. Personality and Individual Differences, 26(6), 1089-1102. https://doi.org/10.1016/S0191-8869(98)00214-1

Paechter, M., Macher, D., Martskvishvili, K., Wimmer, S., \& Papousek, I. (2017). Mathematics Anxiety and Statistics Anxiety. Shared but Also Unshared Components and Antagonistic Contributions to Performance in Statistics. Frontiers in Psychology, 8, 1196.

Park, S. (2003). Research Methods as a Core Competency. Journal of Education for Library and Information Science, 44(1), 17. https://doi.org/10.2307/40323939

Patka, M., Miyakuni, R., \& Robbins, C. (2017). Experiential Learning: Teaching Research Methods with PhotoVoice. The Journal of Counselor Preparation and Supervision. https://doi.org/10.7729/92.1183

Pfeffer, C. A., \& Rogalin, C. L. (2012). Three Strategies for Teaching Research Methods: A Case Study. Teaching Sociology, 40(4), 368-376. https://doi.org/10.1177/0092055X12446783

Rodarte-Luna, B., \& Sherry, A. (2008). Sex differences in the relation between statistics anxiety and cognitive/learning strategies. Contemporary Educational Psychology, 33(2), 327-344. https://doi.org/10.1016/j.cedpsych.2007.03.002 
Manu, J. \& Owusu-Ansah, C.M. (2019). The Impact of Demographic Factors on Pre-Service Teachers' Perception of Educational Research: Findings from a Private University

Schutt, R. K., Hubert M. B. J., \& Theodore, C. W. (1984). Goals and Means for Research Methods Courses. Teaching Sociology, 11(3), 235-58.

Slootmaeckers, K., Kerremans, B., \& Adriaensen, J. (2014). Too afraid to learn: Attitudes towards statistics as a barrier to learning statistics and to acquiring quantitative skills. Politics, 34(2), 191-200.

Tonsing, K. N. (2018). Instructor immediacy and statistics anxiety in social work undergraduate students. Social Work Education, 37(2), 223-233.

Ulrich, A. (n.d.). Using Mathematical Research Methods to Solve a Problem in Music Theory Instruction, Specifically, the Teaching of Secondary Dominant Chords. 15.

Vasquez-Colina, M. D., Maslin-Ostrowski, P., \& Baba, S. (n.d.). Tapping into Graduate Students' Collaborative Technology Experience in a Research Methods Class: Insights on Teaching Research Methods in a Malaysian and American Setting. 13.

Walsh, J. J., \& Ugumba-Agwunobi, G. (2002). Individual differences in statistics anxiety: the roles of perfectionism, procrastination and trait anxiety. Personality and Individual Differences, 33(2), 239-251. https://doi.org/10.1016/S0191-8869(01)00148-9

Zare, H., Rastegar, A., \& Hosseini, S. M. D. (2011). The relation among achievement goals and academic achievement in statistics: the mediating role of statistics anxiety and statistics selfefficacy. Procedia - Social and Behavioral Sciences, 30, 1166-1172. https://doi.org/10.1016/j.sbspro.2011.10.227 